\title{
Relação entre o uso descontrolado de bebidas alcoólicas e perda de memória
}

\author{
Relationship between uncontrolled use of alcoholic beverages and memory loss \\ Relación entre el uso no controlado de bebidas alcohólicas y la pérdida de memoria
}

Recebido: 17/01/2022 | Revisado: 23/01/2022 | Aceito: 31/01/2022 | Publicado: 01/02/2022

\author{
Isabela Moreira Melo \\ ORCID: https://orcid.org/0000-0002-9669-3619 \\ Instituto Master de Ensino Presidente Antônio Carlos, Brasil \\ E-mail: isabela.melo@imepac.edu.br \\ Jorge Vieira Mesquita \\ ORCID: https://orcid.org/0000-0002-1856-4141 \\ Centro Universitário de Patos de Minas, Brasil \\ E-mail: jorgemesquita@unipam.edu.br \\ Tatiana Maciel \\ ORCID: https://orcid.org/0000-0003-4535-6791 \\ Centro Universitário de Patos de Minas, Brasil \\ E-mail: tatianamaciel@unipam.edu.br
}

\begin{abstract}
Resumo
O consumo de bebidas alcoólicas é relacionado como causa de mais de 200 tipos de doenças, principalmente, cirrose hepática, doenças cardiovasculares e vários tipos de câncer. $\mathrm{O}$ uso leve-moderado de bebidas alcoólicas, ao contrário do consumo pesado, não possui claros fatores de influência para as principais doenças citadas. $\mathrm{O}$ presente artigo teve como objetivo geral elucidar a relação do consumo descontrolado de substâncias alcoólicas com a perda de memória, baseado em pesquisas de alta credibilidade. Tratou-se de uma revisão exploratória integrativa de literatura com base na análise de onze artigos selecionados, os quais abordaram as consequências do consumo do álcool em quantidades suficientes capazes de promover alterações na homeostase do sistema nervoso central. Por meio desta revisão da neuropatologia humana relacionada ao álcool foi possível identificar alguns principais fatores que justificam as patologias causadas pelo consumo de bebidas alcoólicas. Os resultados mostraram que o consumo excessivo de álcool afeta negativamente os processos de memória episódica verbal, ou seja, armazenamento e lembrança, bem como o monitoramento de tarefas de aprendizagem verbal. Além da perda de memória, outras patologias se destacaram em todos os estudos, dentre elas tem-se os danos metabólicos ao sistema nervoso central, os danos ao hipocampo e córtex frontal, a perda da flexibilidade cognitiva e o envelhecimento acelerado. Conclui-se que existe uma relação negativa entre o consumo excessivo de substâncias alcoólicas e a perda de memória.
\end{abstract}

Palavras-chave: Abuso de bebidas alcoólicas; Doenças do Sistema Nervoso Central; Perda de memória.

\begin{abstract}
The consumption of alcoholic beverages is related as a cause of more than 200 types of diseases, mainly liver cirrhosis, cardiovascular diseases and several types of cancer. The light-moderate use of alcoholic beverages, unlike heavy consumption, does not have clear influencing factors for the main diseases mentioned. This article aimed to elucidate the relationship between uncontrolled consumption of alcoholic substances and memory loss, based on highly credible research. It was an integrative exploratory literature review based on the analysis of eleven selected articles, which addressed the consequences of alcohol consumption in sufficient quantities capable of promoting changes in the homeostasis of the central nervous system. Through this review of human neuropathology related to alcohol, it was possible to identify some main factors that justify the pathologies caused by the consumption of alcoholic beverages. The results showed that excessive alcohol consumption negatively affects verbal episodic memory processes, i.e. storage and recall, as well as monitoring of verbal learning tasks. In addition to memory loss, other pathologies stood out in all studies, including metabolic damage to the central nervous system, damage to the hippocampus and frontal cortex, loss of cognitive flexibility and accelerated aging. It is concluded that there is a negative relationship between excessive consumption of alcoholic substances and memory loss.
\end{abstract}

Keywords: Alcohol abuse; Central Nervous System Disease; Memory loss.

\section{Resumen}

El consumo de bebidas alcohólicas se relaciona como causa de más de 200 tipos de enfermedades, principalmente cirrosis hepática, enfermedades cardiovasculares y varios tipos de cáncer. El consumo ligero-moderado de bebidas alcohólicas, a diferencia del consumo elevado, no tiene factores claros que influyan en las principales enfermedades mencionadas. Este artículo tuvo como objetivo dilucidar la relación entre el consumo descontrolado de sustancias alcohólicas y la pérdida de memoria, con base en investigaciones altamente confiables. Fue una revisión de literatura exploratoria integradora basada en el análisis de once artículos seleccionados, que abordaron las consecuencias del 
consumo de alcohol en cantidades suficientes capaces de promover cambios en la homeostasis del sistema nervioso central. A través de esta revisión de la neuropatología humana relacionada con el alcohol, fue posible identificar algunos factores principales que justifican las patologías provocadas por el consumo de bebidas alcohólicas. Los resultados mostraron que el consumo excesivo de alcohol afecta negativamente los procesos de memoria episódica verbal, es decir, el almacenamiento y el recuerdo, así como el seguimiento de las tareas de aprendizaje verbal. Además de la pérdida de memoria, en todos los estudios se destacaron otras patologías, como daño metabólico en el sistema nervioso central, daño en el hipocampo y la corteza frontal, pérdida de flexibilidad cognitiva y envejecimiento acelerado. Se concluye que existe una relación negativa entre el consumo excesivo de sustancias alcohólicas y la pérdida de memoria.

Palabras clave: Abuso de bebidas alcohólicas; Enfermedades del Sistema Nervioso Central; Pérdida de memoria.

\section{Introdução}

Do uso social ao problemático, o álcool é a droga mais consumida no mundo. No Brasil, cerca de $52 \%$ da população faz uso de bebidas alcoólicas com alguma frequência, sendo que, em 2010, o total consumido de álcool (puro) per capita no país, entre indivíduos acima de 15 anos, foi estimado em 7,5 a 9,9 litros (WHO, 2016).

Em nível mundial, as doenças relacionadas ao alcoolismo têm aumentado nas últimas décadas, uma vez que o uso de bebidas alcoólicas passou de oitavo lugar em 1990 para quinto em 2010 (Sanchez, 2017). Esses dados mostram que o uso descontrolado dessas bebidas tornou o uso do álcool um fator primordial de risco para a incapacidade e para a morte de pessoas entre 15 a 49 anos de idade, em diversos países. Atualmente o alcoolismo é classificado como um dos principais fatores maléficos para a saúde pública.

Baseado em dados da World Health Organização (WHO), o consumo do álcool é relacionado como a causa de mais de 200 tipos de doenças, pincipalmente, cirrose hepática, doenças cardiovasculares e vários tipos de câncer (Kojuma, 2017). Apesar de poucos dados com evidências fortes e muitas controvérsias, o estudo de Kojima (2017) aponta a diferença entre o consumo de álcool leve-moderado para consumo pesado, identificando que o uso leve-moderado não possui claros fatores de influência para as principais doenças citadas.

No entanto, Goldstein Shelly (1980) dizem que mais de 70\% de indivíduos que possuem transtornos relacionados ao uso de álcool demonstram algum grau de desordem patológica no cérebro, principalmente em regiões ligadas ao desenvolvimento de Alzheimer. Com isso, os resultados de seus estudos apontam que, independente do volume ingerido por dia, o uso de álcool acarreta experiência de declínio no sistema cognitivo e acelera o processo de envelhecimento.

É importante ressaltar que indivíduos dependentes de álcool podem apresentar neuropatia periférica caracterizada por formigamento ou dormência, especialmente nas mãos e nos pés. Uma síndrome neurológica progressiva que afeta a marcha e a postura, muitas vezes acompanhada de nistagmo, pode resultar de atrofia do cerebelo devido a toxicidade do álcool. Já as síndromes neurológicas que resultam da deficiência de tiamina secundária em indivíduos que consomem exageradamente bebidas alcoólicas, como: a síndrome de Wernicke, que consiste em encefalopatia, movimento muscular descoordenado e fraqueza muscular ocular; e a síndrome de Korsakoff que é caracterizada por amnésia, são mais raras. (Clapp et al., 2014).

Diante do exposto, esse estudo apresenta como hipótese o fato de que o uso abusivo de substâncias alcoólicas pode acarretar vários danos à saúde, tanto física quanto mental, estando relacionado principalmente com a proporcionalidade de volume ingerido, bem como, o período de tempo de uso.

A principal motivação para sustentar o presente estudo consistiu em realizar uma revisão exploratória do tipo integrativa, no intuito de verificar a influência mútua entre a utilização descontrolada de álcool e a perda de memória, aprofundando a compreensão das mais recentes estruturas sociais. Sendo assim, o presente artigo teve como objetivo relacionar o uso descontrolado de substâncias alcoólicas em adultos jovens com a perda de memória, baseado em pesquisas com alta credibilidade. 


\section{Metodologia}

O presente estudo consiste de uma revisão exploratória integrativa de literatura. A revisão integrativa foi realizada em seis etapas: 1) identificação do tema e seleção da questão norteadora da pesquisa; 2) estabelecimento de critérios para inclusão e exclusão de estudos e busca na literatura; 3) definição das informações a serem extraídas dos estudos selecionados; 4) categorização dos estudos; 5) avaliação dos estudos incluídos na revisão integrativa e interpretação e 6) apresentação da revisão (Souza et al., 2010).

$\mathrm{Na}$ etapa inicial, para definição da questão de pesquisa utilizou-se da estratégia PICO (Acrômio para Patient, Intervention, Comparation e Outcome) (Santos et al., 2007). Assim, definiu-se a seguinte questão central que orientou o estudo: Há evidências de que o uso descontrolado de bebidas alcoólicas causa perda de memória em adultos na faixa etária de 18 anos a 35 anos?

Nela, observa-se o P - adultos com faixa etária de 18 a 35 anos; o I - uso descontrolado de substâncias alcoólicas; o C adultos que não consomem descontroladamente bebidas contendo álcool; e o O - houve perda de memória.

Para responder a esta pergunta foi realizada a busca de artigos envolvendo o desfecho pretendido utilizando as terminologias cadastradas nos Descritores em Ciências da Saúde (DeCS) criados pela Biblioteca Virtual em Saúde desenvolvido a partir do Medical Subject Headings da U.S. National Library of Medicine, que permite o uso da terminologia comum em português, inglês e espanhol. Os descritores utilizados foram: alcoholism e memory loss. Para o cruzamento das palavras-chave utilizou-se os operadores booleanos 'and' e 'or'.

Realizou-se um levantamento bibliográfico por meio de buscas eletrônicas nas seguintes bases de dados: Biblioteca Virtual de Saúde (BVS), Scientific Eletronic Library Online (SciELO), National Library of Medicine (PubMed) e EbscoHost.

A busca foi realizada no mês de agosto de 2021. Como critérios de inclusão, limitou-se a artigos escritos em português e inglês, publicados nos últimos 6 anos (2015 a 2021), que abordassem o tema pesquisado e que estivessem disponíveis eletronicamente em seu formato integral. Foram excluídos os artigos que não obedeceram aos critérios de inclusão.

Após o levantamento das publicações, considerando os critérios de inclusão e exclusão, foi feita a leitura do título e do resumo, seguida da leitura na íntegra, o que resultou na seleção de 11 artigos para análise final e construção da revisão, conforme Figura 1. 
Figura 1: Fluxograma sobre a busca e a inclusão dos artigos.

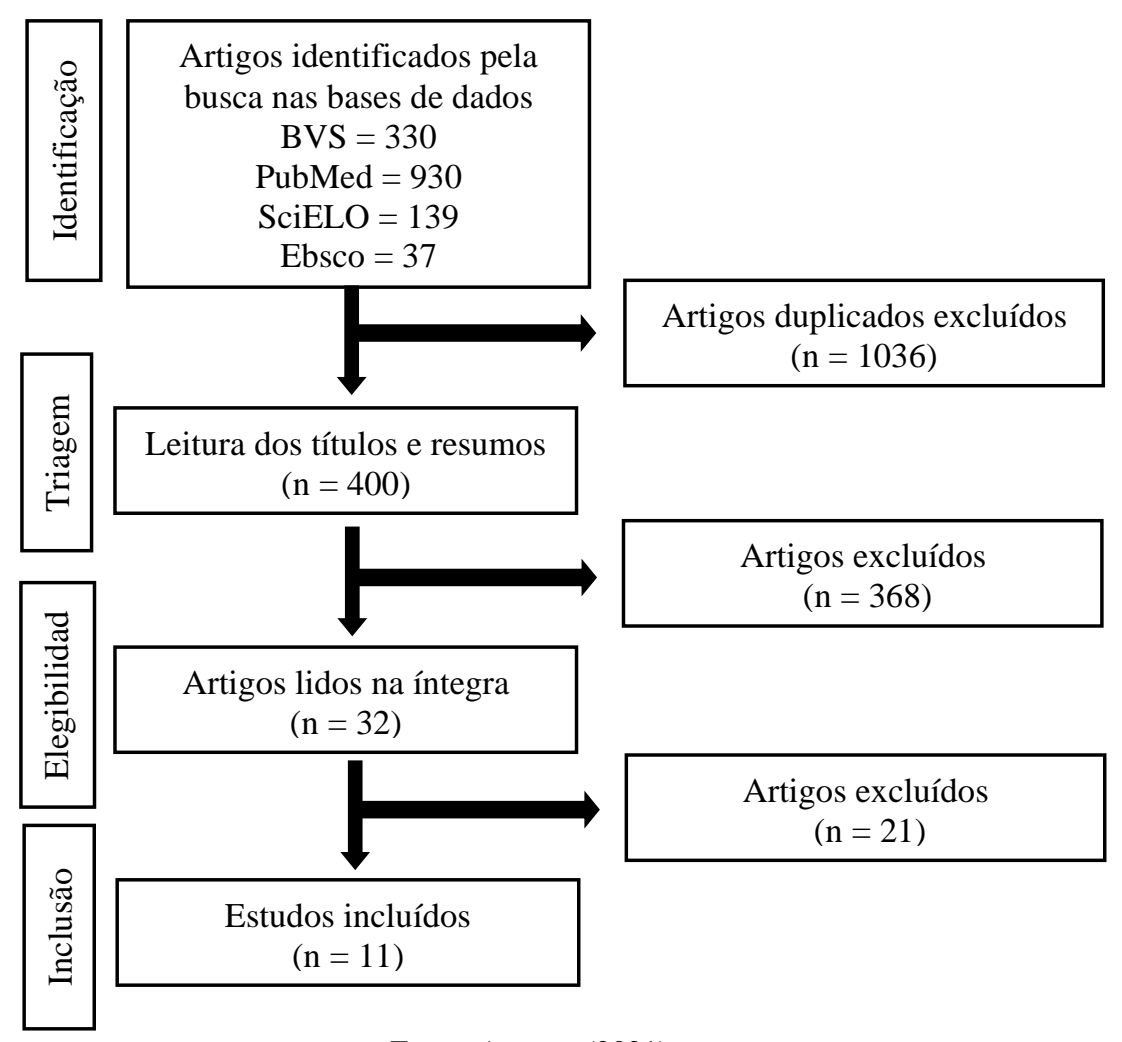

Fonte: Autores (2021).

Posteriormente à seleção dos artigos, realizou-se um fichamento das obras afim de coletar e de analisar os dados obtidos.

\section{Resultados}

Foram selecionados onze artigos que estão presentes no quadro 1. As publicações abordaram as consequências do consumo do álcool em quantidades suficientes capazes de promover alterações na homeostase do sistema nervoso central. Encontrou-se diversos tipos de estudos e diversas regiões estudadas. Houve uma prevalência nos artigos de revisão sistêmica e todos os trabalhos foram publicados no período entre 2015 e 2021. Vale ressaltar que os artigos foram publicados em revistas com alto fator de impacto.

Dentre os efeitos diretos do consumo excessivo de bebidas alcoólicas destacam-se: aumento do risco de desenvolvimento de patologias (mentais e físicas), desenvolvimento de ansiedade, depressão, déficit cognitivo e prática de outros comportamentos de risco, como dirigir alcoolizado, envolver-se em brigas e estimular uso de substâncias ilícitas.

Quadro 1: Características dos estudos sobre o uso de bebidas álcoolicas relacionado com a perda de memória.

\begin{tabular}{|c|c|c|}
\hline Autor(es) e ano & Metodologia & \multicolumn{1}{c|}{ Principais resultados e conclusão } \\
\hline $\begin{array}{c}\text { DE LA MONTE; } \\
\text { KRI } \\
2015\end{array}$ & $\begin{array}{c}\text { Revisão de } \\
\text { literatura }\end{array}$ & $\begin{array}{l}\text { O tema mais abordado foi o etanol como causa de danos metabólicos e tóxicos diretos aos neurônios e } \\
\text { células gliais. As principais consequências incluem função prejudicada de astrócitos e oligodendrócitos, } \\
\text { levando à patologia neuronal, incluindo sinaptogênese reduzida, manutenção de sinapses e } \\
\text { sobrevivência celular. A patologia da substância branca varia de desmielinização a desmielinização e } \\
\text { degeneração da mielina, e ocorre em todas as formas de patologia do SNC relacionada ao álcool. }\end{array}$ \\
\hline $\begin{array}{c}\text { SALAS-GOMEZ } \\
\text { et al. } \\
2016\end{array}$ & $\begin{array}{c}\text { Estudo de } \\
\text { coorte }\end{array}$ & $\begin{array}{l}\text { Sugerem que o consumo intermitente de grandes quantidades de álcool em um curto período de tempo } \\
\text { está associado a um impacto significativo na função cognitiva em adultos jovens, o domínio mais } \\
\text { suscetível são as funções executivas e, em particular, a flexibilidade cognitiva. As mulheres podem ser } \\
\text { mais suscetíveis a esse dano e seu efeito pode ser cumulativo em uma idade precoce. }\end{array}$ \\
\hline
\end{tabular}




\begin{tabular}{|c|c|c|}
\hline $\begin{array}{l}\text { SILVERI et al. } \\
2016\end{array}$ & $\begin{array}{l}\text { Revisão de } \\
\text { literatura }\end{array}$ & $\begin{array}{l}\text { Esta revisão fornece uma visão abrangente dos estudos existentes de ressonância magnética (RM) de } \\
\text { usuários adolescentes de álcool e drogas. A alteração mais comum relatada nas substâncias usadas e } \\
\text { nas modalidades de RM está no lobo frontal ( } 63 \% \text { dos estudos publicados). Isso não é surpreendente, } \\
\text { visto que esta é a última região a atingir a idade neurobiológica adulta. Comparativamente, a evidência } \\
\text { é menos consistente em relação às alterações em regiões que amadurecem mais cedo (por exemplo, } \\
\text { amígdala, hipocampo), no entanto, técnicas mais novas agora permitem investigações além das } \\
\text { abordagens regionais que estão descobrindo vulnerabilidades no nível da rede. }\end{array}$ \\
\hline $\begin{array}{c}\text { ABRAHAO et al. } \\
2017\end{array}$ & $\begin{array}{l}\text { Revisão de } \\
\text { literatura }\end{array}$ & $\begin{array}{l}\text { O número de alvos diretos e indiretos da ação do etanol, embora numerosos, ainda são limitados o } \\
\text { suficiente para permitir a avaliação de muitas ações de drogas que influenciam fortemente os circuitos } \\
\text { e o comportamento. Além disso, alguns alvos (por exemplo, GlyRs, liberação de GABA, NMDARs, } \\
\text { GIRK, BK e SK) medeiam os efeitos do etanol em vários neurônios e sinapses em todo o cérebro. }\end{array}$ \\
\hline $\begin{array}{l}\text { CARBIA et al. } \\
2017\end{array}$ & $\begin{array}{l}\text { Estudo de } \\
\text { coorte }\end{array}$ & $\begin{array}{l}\text { Apenas o uso extremo de bebidas alcoólicas (mais de } 10 \text { drinques por ocasião) teve déficits no } \\
\text { aprendizado verbal e na memória nesta tarefa. Sneider et al., descobriram que jovens que consomem } \\
\text { bebidas em excesso demonstraram aprendizagem inferior (menos palavras na primeira e segunda } \\
\text { tentativas de aprendizagem) e reconhecimento (erros de omissão e comissão) no CVLT (California } \\
\text { Verbal Learning Test), interpretado como déficits de memória verbal. }\end{array}$ \\
\hline $\begin{array}{l}\text { CARBIA et al. } \\
2018\end{array}$ & $\begin{array}{l}\text { Revisão de } \\
\text { literatura }\end{array}$ & $\begin{array}{l}\text { Há evidências substanciais de uma associação entre beber em excesso e déficits de memória verbal e } \\
\text { fraqueza em alguns déficits executivos, especialmente no controle inibitório. Binge drinking (BD) } \\
\text { podem exibir deficiências no automonitoramento de informações na memória de trabalho, flexibilidade } \\
\text { cognitiva e memória prospectiva, embora essas dificuldades mereçam mais exploração. Ambos os } \\
\text { sexos parecem ser afetados de forma semelhante. O início da bebida em idade precoce parece ter um } \\
\text { impacto negativo sobre a cognição. No contrário, atenção, velocidade de processamento, manutenção } \\
\text { de informações em WM, planejamento, livre a recordação retardada da memória visuoespacial e as } \\
\text { habilidades de construção visuoespacial parecem ser relativamente intactos. Espera-se que as } \\
\text { desvantagens sejam maiores em adolescentes com comorbidade. Estudos prospectivos devem separar } \\
\text { diferenças pré-existentes de alterações derivado especificamente da neurotoxicidade do álcool e } \\
\text { analisar os efeitos cumulativos de manter as trajetórias BD. }\end{array}$ \\
\hline NUNES et al. 2019 & $\begin{array}{l}\text { Revisão de } \\
\text { literatura }\end{array}$ & $\begin{array}{l}\text { A resposta neuroimune à exposição ao etanol varia em função do estado ativo (intoxicação ou sequelas } \\
\text { neurológicas de deficiência de tiamina 'TD'), recuperação (após normalização da tiamina) ou } \\
\text { abstinência (retirada aguda ou livre de álcool a longo prazo). Durante um estado de deficiência ativa de } \\
\text { tiamina, há um aumento maciço de genes e proteínas neuroimunes no tálamo e aumentos significativos } \\
\text { no hipocampo e no córtex frontal. O etanol 'tipo binge', intermitente durante o período da adolescência } \\
\text { produz uma resposta neuroinflamatória intermediária no hipocampo e no córtex frontal, que pode } \\
\text { persistir na idade adulta. A indução de genes neuroimunes por exposição excessiva ao consumo de } \\
\text { álcool provavelmente leva à excitabilidade neuronal e estresse oxidativo, que pode desencadear a } \\
\text { neurodegeneração. Há alguma sobreposição no dano cerebral relacionado ao álcool produzida por essas } \\
\text { manifestações: perda de células colinérgicas no prosencéfalo basal, funcionamento hipocolinérgico, } \\
\text { redução da neurogênese hipocampal, bem como perda de matéria cinzenta e branca cortical frontal } \\
\text { (afetando diretamente a perda de memória). }\end{array}$ \\
\hline ZAHR et al. 2019 & $\begin{array}{l}\text { Revisão de } \\
\text { literatura }\end{array}$ & $\begin{array}{l}\text { Os resultados fornecem evidências iniciais de subcampos do hipocampo sensíveis à idade, alcoolismo } \\
\text { e sua interação e sugerem que CA2 e CA3 pode potencialmente distinguir transtornos por uso de álcool } \\
\text { (AUD) de doença de Alzheimer (AD). Uma amostra maior estudada longitudinalmente pode ajudar a } \\
\text { revelar funções relacionadas aos volumes do subcampo do hipocampo. }\end{array}$ \\
\hline $\begin{array}{l}\text { SULLIVAN; } \\
\text { PFEFFERBAUM } \\
2019\end{array}$ & $\begin{array}{l}\text { Revisão de } \\
\text { literatura }\end{array}$ & $\begin{array}{l}\text { Evidências para interações entre transtorno por uso de álcool-envelhecimento, indicativas de } \\
\text { envelhecimento acelerado, juntamente com o aumento do consumo de álcool em adultos de meia-idade } \\
\text { e mais velhos, colocam os bebedores idosos em risco especial de desenvolver declínio cognitivo e } \\
\text { possivelmente demência. }\end{array}$ \\
\hline $\begin{array}{l}\text { GIERSKI et al. } \\
2020\end{array}$ & $\begin{array}{l}\text { Estudo de } \\
\text { coorte }\end{array}$ & $\begin{array}{l}\text { O consumo excessivo de álcool impacta negativamente os processos de memória episódica verbal (ou } \\
\text { seja, armazenamento e lembrança), bem como o monitoramento de tarefas de aprendizagem verbal. } \\
\text { Indo além da concepção categórica de consumo excessivo de álcool, descobrimos que os níveis de } \\
\text { eficiência desses processos de memória foram sistematicamente associados ao número de episódios de } \\
\text { intoxicação nos últimos } 6 \text { meses, destacando a natureza particularmente prejudicial da intoxicação } \\
\text { repetida por álcool para processos de memória. }\end{array}$ \\
\hline $\begin{array}{l}\text { SAVAGE et al. } \\
2021\end{array}$ & $\begin{array}{l}\text { Revisão de } \\
\text { literatura }\end{array}$ & $\begin{array}{l}\text { Exposição a altos níveis de álcool durante o desenvolvimento do cérebro danifica o núcleo talâmico } \\
\text { anterior e no núcleo reuniens. Exposição de longo prazo ao etanol (mais de } 6 \text { meses no roedor) na idade } \\
\text { adulta torna-se confundido com deficiência de tiamina. No entanto, a deficiência extensa de tiamina é } \\
\text { ligada à patologia da linha média (ATN, IML, gelatinosus e núcleos posteriores), mas poupa a perda } \\
\text { de células da linha média ventral. No entanto, dado que o córtex pré-frontal recebe projeções aferentes } \\
\text { de um grande número de núcleos talâmicos, incluindo os núcleos da linha média anterior, intralaminar, } \\
\text { uma gama de disfunção frontocortical (desinibição, memória de trabalho fraca, inflexibilidade } \\
\text { cognitiva e comportamental) é observada após o desenvolvimento ou exposição ao etanol de adultos. } \\
\text { Há também disfunção hipocampal (navegação espacial e memória espacial prejudicadas, disfunção } \\
\text { configural) após exposição ao álcool que é devido à patologia do hipocampo. }\end{array}$ \\
\hline
\end{tabular}

Fonte: Autores (2021). 


\section{Discussão}

O levantamento bibliográfico nas bases de dados evidenciou que a literatura sobre a relação entre o uso descontrolado de bebidas alcoólicas e a perda de memória é abundante e aborda diferentes padrões de mensuração de consumo de bebidas e também diferentes patologias associadas a esse consumo.

Em relação à qualidade dos estudos abordados, tratou-se da análise de estudos publicados em revistas de alta classificação de qualis com garantia de estudos certificados. Chama a atenção o uso de passos metodológicos imprescindíveis, como classificação para análise de artigos, artigos realizados com identificação de resultados por imagens de alta qualidade e adequados critérios de seleção de literatura.

Nesta revisão investigativa foi possível identificar duas categorias relacionadas ao tema em estudo, a saber: o consumo excessivo de substâncias alcoólicas afeta negativamente os processos de memória e a fisiologia do desenvolvimento do SNC (efeitos do álcool na inibição do desenvolvimento de células).

\subsection{Relação entre o consumo excessivo de bebidas alcoólicas e a perda de memória}

Os resultados mostram que o consumo excessivo de álcool afeta negativamente os processos de memória episódica verbal, ou seja, armazenamento e lembrança, bem como o monitoramento de tarefas de aprendizagem verbal. Indo além da concepção categórica de consumo excessivo de álcool, foi possível identificar que os níveis de eficiência desses processos de memória foram sistematicamente associados ao número de episódios de intoxicação nos 6 meses anteriores, destacando a natureza particularmente prejudicial da intoxicação repetida de álcool para processos de memória. No entanto, é possível a existência de um impacto diferencial, uma vez que a memória de trabalho verbal não foi afetada, enquanto a memória episódica verbal foi afetada (Gierski, 2020).

Ademais, a manutenção de um padrão descontrolado de consumo de álcool desde a adolescência até o início da idade adulta está associado a déficits episódicos (especialmente na consolidação da memória) junto com possíveis dificuldades executivas que também contribuem para o desempenho insatisfatório da memória verbal em estudantes universitários saudáveis (Carbia et al., 2017).

Os resultados sugerem que o consumo intermitente de grandes quantidades de álcool em um curto período de tempo está associado a um impacto significativo na função cognitiva em adultos jovens, sendo o domínio mais suscetível as funções executivas e, em particular, a flexibilidade cognitiva. As mulheres podem ser mais suscetíveis a esse dano e seu efeito pode ser cumulativo em uma idade precoce (Salas-Gomez, 2016).

$\mathrm{O}$ estudo indica uma relação entre o monitoramento da resposta atenuada e a gravidade da binge drinking (expressão estrangeira que significa beber em excesso) no contexto de capacidade inibitória preservada e tempos de reação rápidos. O estudo apoia a visão de que o consumo excessivo de álcool é um fenômeno contínuo e não categórico. Diante disso, a gravidade do consumo excessivo de álcool indica um marcador precoce de suscetibilidade para problemas relacionados ao álcool na vida adulta. Assim, é importante para entender por que os bebedores compulsivos continuam seu padrão de consumo de álcool apesar das consequências negativas que isso acarreta (Bø et al., 2016).

Pessoas que consomem bebidas alcoólicas em excesso podem exibir deficiências no automonitoramento de informações da memória de trabalho, flexibilidade cognitiva e memória prospectiva, embora essas dificuldades mereçam mais exploração (Silveri et al., 2016). Há evidências substanciais de uma associação entre consumo excessivo de álcool e déficits de memória verbal e fraqueza em alguns déficits executivos, especialmente no controle inibitório.

Ao examinar a relação entre o volume cerebral e problemas relacionados ao álcool prospectivamente, este estudo fornece algumas das primeiras evidências de que as anormalidades cerebrais são anteriores e predizem o uso problemático de álcool. Este achado tem implicações importantes para a forma como conceituamos as sequelas neurobiológicas do alcoolismo, 
pois sugere que pelo menos algumas das alterações estruturais encontradas em bebedores podem ser pré-mórbidos (Cheetham et al., 2014).

O consumo excessivo de álcool entre os jovens está associado a estruturas corticais e subcorticais menores/mais finas e diminuição da integridade da matéria branca. Consistente em muitos estudos de imagem de ressonância magnética de controle cognitivo, memória de trabalho e aprendizado verbal, jovens compulsivos por bebidas alcoólicas e episódio pesado de consumo excessivo, mostram maior dependência de sistemas fronto-parietais ao realizar essas tarefas. O funcionamento executivo e os sistemas de processamento emocional são redes importantes para futuras investigações relacionadas à tomada de decisão e processamento de recompensas, enquanto circuitos mesolímbicos provavelmente estão envolvidos na resposta elevada a estímulos de álcool em jovens compulsivos por bebidas alcoólicas e episódio pesado de consumo excessivo. Esses achados sugerem que pode haver alterações neurais como resultado do uso pesado de álcool ou marcadores neurais de risco relacionados à vulnerabilidade ao consumo excessivo de álcool durante a adolescência e a idade adulta jovem. Embora alguns achados tenham sido replicados, são necessários maiores esforços para consistência entre as variações de tarefas, análises relatadas, critérios de inclusão para jovens compulsivos por bebidas alcoólicas e episódio pesado de consumo excessivo, bem como estudos longitudinais sobre esse tópico (Cservenka \& Brumback, 2017).

\subsection{Efeitos do álcool no desenvolvimento do SNC}

Os resultados podem ser explicados pelos efeitos do álcool na inibição das células-tronco neurais da neurogênese adulta no hipocampo adolescente. Durante a adolescência, o hipocampo apresenta maior neurogênese do que na idade adulta. Consequentemente, beber excessivamente durante este período pode resultar em uma perda massiva de células que não podem nascer ou sobreviver (Carbia et al., 2017).

É amplamente reconhecido que o abuso crônico de álcool que reduz o volume do hipocampo está associado a déficits na memória episódica. Da mesma forma, foi descoberto que adultos jovens com transtorno por uso de álcool têm um volume hipocampal menor, especialmente o hipocampo esquerdo. No nível neuropsicológico, jovens adultos tiveram um déficit de 10\% na recordação atrasada de informações verbais (Carbia et al., 2017).

A resposta neuroimune à exposição ao etanol varia em função do estado ativo (intoxicação ou sequelas neurológicas da deficiência de tiamina), recuperação (após normalização da tiamina) ou abstinência (retirada aguda ou livre de etanol a longo prazo). Durante um estado ativo de deficiência de tiamina, há um grande aumento nos genes e proteínas neuroimunes dentro do tálamo e aumentos significativos dentro do hipocampo e córtex frontal. O etanol 'tipo binge' intermitente durante o período da adolescência produz uma resposta neuroinflamatória intermediária no hipocampo e frontal córtex que pode persistir na idade adulta. A indução de neuroimune genes por exposição excessiva a álcool provavelmente leva à excitabilidade neuronal e estresse oxidativo, que pode iniciar a neurodegeneração (Nunes et al., 2019).

Os presentes achados fornecem evidências iniciais de subcampos sensíveis à alcoolismo e idade. Com isso, os estudos trazem dados que sugerem que transtornos por uso de álcool podem causar patologias aos subcampos do SNC. No entanto, a idade também interfere nesses resultados, podendo indicar que o indivíduo pode sofrer doença de Alzheimer sem necessariamente ingerir bebidas alcoólicas. Evidências para interações entre envelhecimento e transtornos por uso de bebidas alcoólicas, em adultos de meia-idade e mais velhos, indicam que os bebedores envelhecem com especial risco de desenvolver declínio cognitivo e possivelmente demência. Uma amostra maior estudada longitudinalmente pode ajudar a revelar funções relacionadas aos volumes do subcampo do hipocampo indicativos, ou de Doença de Alzheimer (DA), ou demência (Zahr et al., 2019).

Os danos cerebrais relacionados ao consumo de álcool, podem estar relacionadas com as seguintes manifestações: perda de células colinérgicas no prosencéfalo basal, funcionamento hipocolinérgico, redução do hipocampo neurogênese, bem como 
perda de massa cinzenta e branca cortical frontal. Além disso, a deficiência de tiamina induz seletivamente a lesões significativas, com perda de células na região central do tálamo. Disfunções colinérgicas corticais hipocampais e frontais, também são relatadas, sendo relacionadas a disfunção cognitiva associada com demência (Nunes et al., 2019).

Há também disfunção hipocampal (dificuldade de navegação e memória espacial, disfunção configural) após a exposição ao álcool durante o desenvolvimento e em adultos devido à patologia hipocampal, bem como danos ao núcleo talâmico anterior. Compreender a especificidade da influência talâmica no circuito corticotalâmico e talâmico-hipocampal fornece uma base muito necessária para a compreensão das consequências dos paradigmas de exposição ao álcool e dos transtornos por uso de álcool (Savage et al., 2021).

Como afirmado, o álcool não é altamente seletivo regionalmente como neurotoxina, mas o tálamo da linha média é um alvo importante. Conforme revisado, núcleos específicos dentro do tálamo apresentam vulnerabilidade única à neurotoxicidade relacionada ao álcool. A exposição a altos níveis de álcool durante o desenvolvimento do cérebro danifica o núcleo talâmico anterior. A exposição de longo prazo ao etanol (mais de 6 meses no roedor) na idade adulta pode ser confundida com a deficiência de tiamina. No entanto, a deficiência extensa de tiamina está ligada à patologia da linha média (núcleo talâmico anterior, IML, gelatinosus e núcleos posteriores), mas poupa a perda de células da linha média ventral. No entanto, dado que o córtex pré-frontal recebe projeções aferentes de um grande número de núcleos talâmicos, incluindo os núcleos da linha média anterior, intralaminar, uma gama de disfunção frontocortical (desinibição, memória de trabalho fraca, inflexibilidade cognitiva e comportamental) é observada após a exposição ao etanol durante o desenvolvimento do jovem adulto (Savage et al., 2021).

Vale ressaltar que, incluindo os principais processos patológicos em cérebros maduros e em desenvolvimento, nervos periféricos e músculos esqueléticos, o tema mais abrangente é que o etanol causa danos metabólicos e tóxicos diretos aos neurônios e às células gliais. As principais consequências incluem função prejudicada de astrócitos e oligodendrócitos, levando a patologia neuronal, incluindo sinaptogênese reduzida, manutenção de sinapses e sobrevivência celular. A patologia da substância branca varia de desmielinização, desmielinização e degeneração da mielina, e ocorre em todas as formas de patologia do Sistema Nervoso Central (SNC) relacionada ao álcool. A natureza, gravidade e distribuição das lesões da substância branca variam com a idade, tempo de exposição e dose de etanol. As consequências da neuropatologia mediada pelo etanol são frequentemente complicadas pela tiamina e outras deficiências nutricionais. A deficiência de tiamina ocorre porque o álcool inibe sua absorção e ações fisiológicas. Embora a deficiência de tiamina por si só seja suficiente para causar encefalopatia de Wernicke e neuropatia periférica, muitos aspectos do SNC adulto e doenças neuromusculares relacionadas ao álcool parecem ser causados por efeitos combinados tanto da deficiência de tiamina quanto da toxicidade do álcool (De la monte \& Kril, 2015).

Como esta revisão indica, os efeitos do etanol nos níveis molecular, celular e de circuito são inúmeros e podem parecer assustadores, especialmente quando comparados a drogas que atuam através de um alvo molecular predominante. No entanto, o número de alvos diretos e indiretos da ação do etanol, embora numerosos, ainda são limitados o suficiente para permitir a avaliação de muitas ações de drogas que influenciam fortemente os circuitos e o comportamento. Além disso, alguns alvos (por exemplo, glicil-tRNA sintetase, liberação de ácido gama-aminobutírico, N-metil-D-aspartatos, canal de potássio de retificação interna acoplada à proteína G) medeiam os efeitos do etanol em vários neurônios e sinapses em todo o cérebro. Ao abandonar uma visão de 'alvo único' das ações do etanol e, em vez disso, examinar quais moléculas são alteradas pelo uso do álcool, os investigadores estão começando a juntar as ações intoxicantes, promotoras de abuso e tóxicas da droga (Abrahao et al., 2017; Roberto \& Varodayan, 2017)

A exposição crônica ao álcool produz uma neuro adaptação significativa no GABAérgico e nas sinapses glutamatérgicas, particularmente no que diz respeito à expressão, localização e função de proteínas sinápticas, canais e receptores, e esses efeitos podem ser tanto do tipo celular, como também, das regiões específicas do cérebro. O desenvolvimento de tolerância e dependência ao álcool são de particular importância clínica, e é provável que essas mudanças adaptativas na 
função do receptor de GABA e glutamato desempenham um papel crítico nestes processos. Fica claro que a maioria dos estudos iniciais que caracterizam os efeitos crônicos do etanol na transmissão GABAérgica se concentrou principalmente nas propriedades pós-sinápticas e na composição das subunidades dos próprios receptores GABAaRs. Algumas das diferenças nos resultados relatados entre os laboratórios podem refletir as diferenças na duração da exposição crônica ao etanol e protocolo, região do cérebro examinada e métodos de avaliação da função do receptor. Coletivamente, esses resultados oferecem forte suporte para a hipótese de que pelo menos algumas das ações crônicas do etanol são mediadas por seus efeitos nas funções neurais associadas ao GABA e transmissão sináptica de glutamato e esses efeitos desempenham um papel importante na manutenção do comportamento de consumo de álcool (Roberto \& Varodayan, 2017).

Considerando as limitações impostas por análises baseadas em aspectos individuais, alguns autores enfatizaram a importância de ampliar as investigações para compreender a influência direta da quantidade consumida e o efeito do álcool na perda de memória. Acrescentaram que, mesmo utilizando técnicas estatísticas sofisticadas, as evidências ainda são insuficientes para consistentemente explicar o papel do efeito do álcool na perda de memória.

\section{Conclusão}

Buscou-se elucidar, por meio desta revisão de literatura, a relação entre o consumo descontrolado de bebidas alcoólicas e a perda de memória. Além da perda de memória, outras patologias se destacaram em todos os estudos, dentre elas os danos metabólicos ao SNC, os danos ao hipocampo e ao córtex frontal, a perda da flexibilidade cognitiva e o envelhecimento acelerado. Os problemas relacionados ao abuso de bebida alcoólica são de ordem tanto física quanto psicológica. Entender o que motiva os indivíduos a consumirem o álcool é de grande importância para o estabelecimento de políticas públicas em saúde e execução de atividades preventivas.

Apesar de décadas de conhecimento dos efeitos neurológicos e neuropatológicos do abuso pesado de álcool, ainda estamos atrasados em nossa compreensão dos espectros e mecanismos da doença, em parte devido a dados clínicos inadequados e à sobreposição entre doenças relacionadas ao álcool e outras doenças metabólicas. Diante disso, foram incluídas publicações do tipo artigo com textos completos, cujo tema principal correspondesse ao descritor ou palavra-chave utilizada. Foram excluídos os artigos que, após análise criteriosa, não atendessem à demanda bibliográfica, o que gera limitações ao estudo principalmente artigos científicos não-disponíveis em formato integral.

Por fim, espera-se que esta breve revisão estimule futuras investigações com a utilização de outras técnicas e métodos de investigação científica que explorem de forma mais profunda a gravidade deste problema aqui abordado.

\section{Referências}

Abrahao, K. P., Salinas, A. G., \& Lovinger, D. M. (2017). Alcohol and the Brain: Neuronal Molecular Targets, Synapses, and Circuits. Neuron, v. 96 (6), 12231238. 10.1016/j.neuron.2017.10.032.

B $\varnothing$, R., Aker, M., Billieux, J., \& Landrø, N. I. (2016). Binge Drinkers Are Fast, Able to Stop - but They Fail to Adjust. J. Int. Neuropsychol. Soc. 22 , 38-46. $10.1017 / \mathrm{S} 1355617715001204$

Carbia, C., Cadaveira, F., Caamaño-Isorna, F., Rodríguez-Holguín, S., \& Corral, M. (2017). Binge drinking during adolescence and young adulthood is associated with deficits in verbal episodic memory. PloS one, 12(2), 01-08. 10.1371/journal.pone.0171393

Carbia, C., López-Caneda, E., Corral, M., \& Cadaveira, F. (2018). A systematic review of neuropsychological studies involving young binge drinkers. Neuroscience and biobehavioral reviews, 90, 332-349. 10.1016/j.neubiorev.2018.04.013

Cheetham, A., Allen, N. B., Whittle, S., Simmons, J., Yücel, M., \& Lubman, D. I. (2014). Volumetric differences in the anterior cingulate cortex prospectively predict alcohol-related problems in adolescence. Psychopharmacology, 231(8), 1731-1742. https://doi.org/10.1007/s00213-014-3483-8

Clapp, P., Wackernah, R., \& Minnick, M. (2014). Alcohol use disorder: pathophysiology, effects, and pharmacologic options for treatment. Substance Abuse and Rehabilitation, 1-. 10.2147/SAR.S37907

Cservenka, A. \& Brumback, T. (2017). The burden of binge and heavy drinking on the brain: effects on adolescent and young adult neural structure and function. Front Psychol. 8, 1111. 0.3389/fpsyg.2017.01111 
Research, Society and Development, v. 11, n. 2, e46411225836, 2022

(CC BY 4.0) | ISSN 2525-3409 | DOI: http://dx.doi.org/10.33448/rsd-v11i2.25836

De la Monte, S. M. \& Kril, J. J. (2014). Human alcohol-related neuropathology. Acta neuropathologica, 127(1), 71-90. 10.1007/s00401-013-1233-3

Gierski, F., Stefaniak, N., Benzerouk, F., Gobin, P., Schmid, F., Henry, A., Kaladjian, A., \& Naassila, M. (2020). Component process analysis of verbal memory in a sample of students with a binge drinking pattern. Addictive behaviors reports, 12, 100323. 10.1016/j.abrep.2020.100323

Kojima, G., Liljas, A. Iliffe, S., Jivraj, S., \& Walters, K. (2017). A systematic review and meta-analysisof prospective associations betweenalcohol consumption and incident frailty. Oxford University Press on behalf of the British Geriatrics Society, 47, 26-34. 10.1093/ageing/afx086

Nunes, P. T., Kipp, B. T., Reitz, N. L., \& Savage, L. M. (2019). Aging with alcohol-related brain damage: Critical brain circuits associated with cognitive dysfunction. International review of neurobiology, 148, 101-168. 10.1016/bs.irn.2019.09.002

Roberto, M. \& Varodayan, F. P. (2017). Synaptic targets: Chronic alcohol actions. Neuropharmacology, 122, 85-99. 10.1016/j.neuropharm.2017.01

Salas-Gomez, D., Fernandez-Gorgojo, M., Pozueta, A., Diaz-Ceballos, I., Lamarain, M., Perez, C., \& Sanchez-Juan, P. (2016). Binge drinking in young university students is associated with alterations in executive functions related to their starting age. PLoS ONE, 11(11), 1-12. https://doi.org/10.1371/journal.pone.0166834

Sanchez, Z. M. (2017). A prática de binge drinking entre jovens e o papel das promoç̃os de bebidas alcoólicas: uma questão de saúde pública. Epidemiol. Serv. Saúde, 26(1), 195-219. http://dx.doi.org/10.5123/s1679-49742017000100020

Santos, C. M. da C., Pimenta, C. A. de M., \& Nobre, M. R. C. (2007). A estratégia PICO para a construção da pergunta de pesquisa e busca de evidências. Rev Latino-am Enfermagem 15(3), 01-04. https://doi.org/10.1590/S0104-11692007000300023

Savage, L. M., Nunes, P. T., Gursky, Z. H., Milbocker, K. A., \& Klintsova, A. Y. Midline Thalamic Damage Associated with Alcohol-Use Disorders: Disruption of Distinct Thalamocortical Pathways and Function. Neuropsychology review, 31(3), 447-471. 10.1007/s11065-020-09450-8

Silveri, M. M., dager, A. D., Cohen-Gilbert, J. E., \& Sneider, J. T. (2016). Neurobiological signatures associated with alcohol and drug use in the human adolescent brain. Neuroscience Biobehavior, 70, 244-259. 10.1016/j.neubiorev.2016.06.042

Souza, M. T. de, Silva, M. D. da, \& Carvalho, R. de (2010). Revisão integrativa: o que é e como fazer. Einstein, 8(11), 102-6. https://doi.org/10.1590/S167945082010RW1134

Sullivan, E. V., \& Pfefferbaum, A. (2019). Brain-behavior relations and effects of aging and common comorbidities in alcohol use disorder: a review. Neuropsychology, 33(6), 760-780. 10.1037/neu0000557

WOrld Health Organization. WHO. (2016). Management of substance abuse. Retrieved October 5, 2021, from http://www.who.int/substance_abuse/en/

Zahr, N. M., Pohl, K. M., Saranathan, M., Sullivan, E.V., \& Pfefferbaum, A. (2019). Hippocampal subfield CA2+3 exhibits accelerated aging in Alcohol Use Disorder: A preliminary study. NeuroImage. Clinical, 22, 1-8. 10.1016/j.nicl.2019.101764 